This paper is accepted for publication in

Innovative Higher Education, Volume 32, Number 4.

Reprinted with permission from the publisher Springer Netherlands.

The original publication is available at www.springerlink.com

\title{
Integration of Sustainability in Higher Education: A Study with International Perspectives
}

\author{
Kaisu Sammalisto and Thomas Lindhqvist
}

\begin{abstract}
Kaisu Sammalisto bolds the Licentiate of Technology from Lund University and the M.B.A from Uppsala University, the M.Sc. Eng. from Abo Akademi University; and she is a doctoral student at the International Institute for Industrial Environmental Economics at Lund University. She was working as Dean for Environmental Management and Education at the University of Gävle in Sweden during the implementation of a certified Environmental Management System (EMS) in 2001-2005. She has previously studied environmental management system implementation in Small and Medium Sized Enterprises and continues her studies of the same in university settings. Thomas Lindhqvist is Associate Professor in Cleaner Product Systems at the International Institute for Industrial Environmental Economics (IIIEE), Lund University. He has a B.A. in languages, a B.A. in Business Administration, a M.Sc. in Engineering Physics, and a Ph.D. in Industrial Environmental Economics, all from Lund University. E-mail address: Kaisu.Sammalisto@hig.se.
\end{abstract}

Abstract: This study examined the impact of a procedure implemented and used at one Swedish university to promote integration of the concept of sustainability into courses. The study is based on a literature study and a case study at the University of Gävle in Sweden, where faculty members are asked to classify their courses and research funding applications regarding the contributions thereof to sustainable development. The results of the study indicated that this procedure can indeed stimulate faculty members to integrate sustainable development in their courses. It is clear that the reported changes in courses were also influenced by other factors such as the increased general awareness of environmental issues

Keywords: Curriculum, environmental management, indicator, sustainable development

In 2006 the Swedish Parliament amended the Swedish Higher Education Act to include the statement: "Universities shall, in their activities, work for sustainable development, which means that present and future generations are assured of having a healthy and good environment, economy, and social welfare and justice" (SFS 1992:1434, translation by authors). The amendment is supported by the fact that years 2005 to 2014 have been declared the United Nations Decade of Education for Sustainable Development (UNESCO, 2002), which provides a tremendous opportunity and challenge for all levels of education.

\section{The Problem}

One must ask, however, what the phrase "in their activities, work for sustainable development" means for institutions of higher education? As illustrated by the quotation from the Swedish Higher Education Act above, the concept of sustainable development incorporates not only an environmental dimension but also economic and social dimensions, and 
frequently also a cultural dimension. That education and research play a key role for the long-term development of society is hardly disputed by anyone; but how to integrate sustainability effectively into higher education and, in particular, into the curriculum and the design of research projects is still a debated issue.

\section{Background}

In higher education, the level of integration of the concept of sustainable development can range from mere formulations of policy statements to integration into courses, curricula, and other selected activities for a total reform of the educational system. A more practical approach to promote sustainable development is to work with tangible environmental impacts. In Europe, North America, and other regions there are good examples indicating that greening the campus, e.g., improved waste management, energy saving innovations, is making operations more environmentally sustainable. Such changes do not meet major resistance since they lead to economic savings (Fisher, 2003; Herremans \& Allwright, 2000; Price, 2005). There are also several studies of calculations of ecological footprints ${ }^{6}$ for universities (Flint, 2001; Ruy \& Brody, 2006; Segalàs, Ferrer-Balas \& Carrillo, 2004). However, the initiatives to promote the concept of sustainability in higher education have so far actually had little impact on education (Wright, 2004).

Sterling (2004) has presented a model for integration of sustainability in

6 The ecological footprint is defined as the land that would be required to support a certain activity, for instance a specified group's lifestyle, forever. Included in the ecological footprint calculations are both the extraction of raw materials and the absorption of pollution in a long term sustainable way. education, and there is a North American parallel to be found in the discussions of integration of diversity issues (Stanley, 2000-01). Sterling called the first level accommodation "bolting-on", i.e., adding the concept of sustainability to the existing system, which in itself largely remains unchanged. This is "education about sustainability" and can consist of separate courses about sustainability for students.

Sterling called the second level of integration, which is a deeper level of response, "building-in"; and this means that ideas are incorporated into existing systems, e.g., greening the curriculum and institutional operations. This level could be called "education for sustainability", and it includes integrating sustainability issues into regular discipline-specific courses. It aims at creating a connection in the minds of students between the subject in question and sustainable development. Focusing on technical and economic programs as well as teacher training programs, some of the earliest such initiatives in Sweden to work with the greening of higher education were done as projects sponsored by the National Council for Renewal of Higher Education. The results from projects in 27 universities indicated a positive impact on students, particularly for engineering students in the smaller universities. The greening of engineering programs was spread over a larger number of subjects as compared to programs in the discipline of economics, in which greening was limited to the core subjects (Sammalisto, 1999). An approach somewhat similar to the Swedish one has been used in the Netherlands based on disciplinary reviews. This approach poses an intellectual challenge to instructors to integrate sustainability within each discipline by "exploring the relationships between various disciplines and sustainable development" (Appel, Dankelman \& Kuipers, 2004). 
The third level is called transformation, which means a complete re-design of education based on sustainability principles. This level would require a paradigm change so that education would be built on learning as change and education as sustainability. In practice, this would mean that the goal of all education would be sustainable development, and the different disciplines and subjects would all contribute to it. An example of a model for integration to this extent is the one presented by JuárezNájera, Dieleman \& Turpin-Marion (2006). They presented a framework for a culture where holistic understanding is the focus of education rather than specific knowledge or skills: "Students must learn new and sustainable ways of looking at the world, themselves and their professions." (p. 1037).

Though there are quite a few published case studies on the environmental aspect of sustainability, the authors have only been able to find a few dealing with the broader concept of sustainability. Ferrer-Balas, Cruz, Segalàs $\&$ Sans (2006) discussed the difficulty of integrating sustainability in curricula. After studying keywords appearing in course descriptions and objectives at the Technical University of Catalonia since 1997, where $30 \%$ of the final theses now have a chapter with environmental considerations, the researchers concluded: "Due to strong impermeability of the curriculum it has not been possible to deeply revise the curricula from a sustainability perspective, only from the environmental one, mainly by adding contents to it" (p. 3).

A study by Holt (2003) indicated that discipline-specific modules (courses or course components), "when environmental modules are integrated in corporate and management classes" (p. 329), are more important than courses designed to increase awareness of sustainability. This statement, based on a study of the "impact of education and cultural experiences of business school students during their three years at the University" (p. 331), supports the idea of integration rather than separate courses. This finding is contrary to practice in many universities, where the main focus has been on establishing general environmental courses, thus providing an overview of environmental problems, concepts and approaches, rather than linking the concept of sustainability to a particular field of study.

The problem of weak connections between and among statements, policies, and practices has been reported in a number of case descriptions. Segalàs, Cruz \& Mulder (2004) studied the Technical University of Catalonia in Spain, Delft University of Technology in the Netherlands, and Tecnológico de Monterrey in Mexico and concluded that these universities were early adopters of environmental policies and that they have had ambitious plans to also include elements of sustainable development, including values. For various reasons, their goals have not been achieved; and what is offered today is a number of greened, mostly environmentally focused courses, mandatory or optional for the students. Other scholars have identified problems such as lack of highest administrative commitment to work of integrating sustainability, lack of followup procedures, failure to recognise and accept the importance of environmental and sustainability problems, limited time and resources, and the prevailing academic culture (Lidgren, Rodhe \& Huisingh, 2006; Sammalisto \& Arvidsson, 2005; Segalàs, Ferrer-Balas \& Mulder, 2005).

According to Shriberg (2002), issues that are important in assessing sustainability in higher education deal "with the core issues of ecologically, socially and fiscally sustaining society and campus" (p. 256). One must then ask how 
we operationalise these issues. One of the first to make an effort was Penn State Green Destiny Council (2000, p. 4). They defined indicators for higher education based on David Orr's definition of sustainability-based culture (Orr, 1996).

As stated above, there are good examples of campus greening efforts and environmental management. What is lacking, however, is empirical research on this subject; and, even beyond this area, there is a lack of studies on the broader topic of integration of sustainability in education and research. Moreover, available case studies rarely include information about research methods (Corcoran \& Wals, 2004). It is also an important research task to include in the analysis dimensions of sustainable development beyond the environmental.

\section{The Study}

With our study we wanted to contribute to the understanding of how to integrate sustainability into education and research by examining the method for integration and, in particular, the procedure for the classification and review of university courses and research projects for integration of sustainable development at the University of Gävle. This university is the only one in Sweden which has developed a formalised classification procedure for courses and research projects, consisting of a form to be filled out by the responsible instructor/ researcher. Specifically, we wanted to find out how different disciplines integrate sustainability in their courses and how they incorporate a sustainability assessment of the research in the applications for research funding. From the study we then expected to be able to draw implications for other institutions.

This research is part of a bigger effort on the part of the authors to understand the role of environmental management systems $^{7}$ (EMS) in higher education in Sweden. The issue is approached from a six-step model as described in Figure 1 below. Steps 1-3 have been reported in previous publications (Sammalisto, 2004; Sammalisto \& Arvidsson, 2005; Sammalisto \& Brorson, 2006). This article looks closer into part of the fourth step the greening of courses and research efforts.

\section{The Classification Procedure}

In 2005 the University of Gävle had about 750 faculty and staff and 13,500 full and part time students, corresponding to about 6,200 full time equivalent students. The University has six colleges: Business Administration and Economics; Technology and Built Environment; Humanities and Social Sciences; Mathematics, Natural, and Computer Sciences; Education and Psychology; and Health Sciences and Sociology.

7 An environmental management system (EMS) is part of an organization's overall management system and is used to develop and implement its environmental policy. EMS can be certified according to the international standard ISO 14001. Today more than 100,000 organizations, mainly industries, but also a growing number of other types of organizations, have achieved such a certification. The president of the university has the overall responsibility for the EMS and its results, but delegates the responsibilities within the regular university organization so that the objectives can be met. In Sweden the implementation of EMS as a way to work towards sustainable development was initiated by government directives to all public agencies, including the 35 public universities, during the period of 1998-2001. 


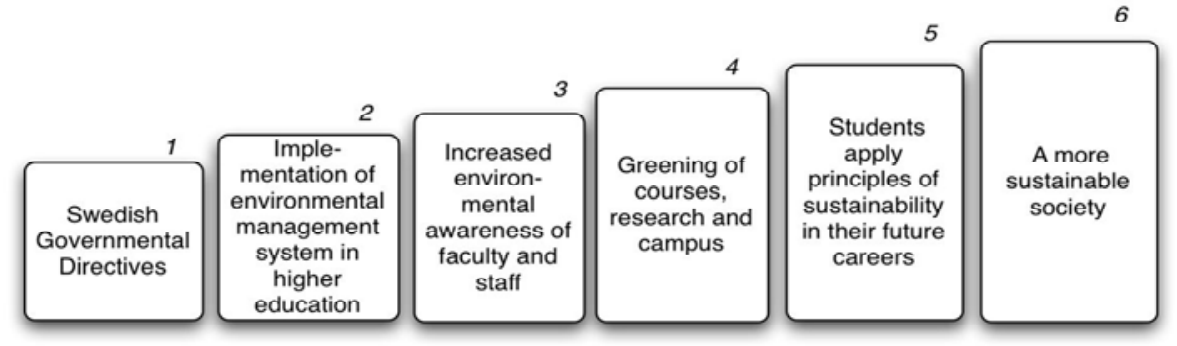

Figure 1. The role of Environmental Management Systems (EMS) in higher education in the steps towards a more sustainable society. (Sammalisto \& Brorson, in press)

As part of the environmental management system, instructors are requested to classify their courses based on their environmental and sustainable development (E/SD) content, using the definitions provided and the Policy for Environment and Sustainable Development of the University as guidance. The classification, which was developed by the University Environmental Council ${ }^{8}$ and discussed in meetings in the different colleges, is very simple, and the instructor just has to check one of four boxes according to the definitions shown below:

A - A major part of the course has $\mathrm{E} / \mathrm{SD}$ content;

B - The course has some E/SD content;

${ }^{8}$ Every College at the University has appointed a staff member to act as environmental coordinator. These together with the vice-president (acting as chairperson) and student representatives form the Environmental Council of the University. The coordinator is responsible for collecting information about the environmental and sustainability performance of the institution, reporting to the Environmental Council, and giving advice to faculty and staff in the college.
C - The course has no E/SD content, but has the potential for this; or

$\mathrm{D}-\mathrm{E} / \mathrm{SD}$ content is not relevant for the course.

In addition space is provided for writing an explanation of the reason(s) why the course was so classified. It is not mandatory to provide such an explanation, but the administration recommends doing so. ${ }^{9}$

Although the classification of the courses was to take place whenever a new course was introduced or an existing one revised, all colleges voluntarily also started working on existing courses. The system was implemented in 2002, and by the end of the $200582 \%$ of all current courses at the University had been reviewed in this regard. By decision of the President, a similar classification form for inclusion with applications for research funding was introduced in 2005. The manager of the research project is responsible for this classification. For 2005, $90 \%$ of the applications included an $\mathrm{E} / \mathrm{SD}$

9 More detailed information about the environmental program, for instance the policy, the environmental management system, and the course and research classification forms can be found at: www.hig.se/miljo/. 
classification. However, not providing an E/SD classification does not lead to any sanction.

\section{The Method}

For this study we reviewed the completed classification forms for all the 1317 current courses and all the 125 research funding applications for the year 2005. Swedish law guarantees access to this type of information in any state organization, and this type of study does not require any form of institutional approval. The explanations provided in the classification forms were interpreted by two researchers independently and gathered in an Excelsheet as the basis for statistical presentation. We should point out that the amount of effort spent on classifying the courses and research projects is likely to be very different on the part of the individual instructors/ researchers; but the initial interpretations by the two researchers proved to be identical for all but a small number of forms, for which consensus was found through discussion.

In addition to studying the classification forms, 15-minute semistructured interviews were conducted with 13 instructors/researchers in order to explore their experiences of working with the classification procedure and their understanding of the concept of sustainability; and we wanted to understand in more detail how the work of integrating sustainability in courses has progressed. The instructors, most of them also active researchers, were chosen partly based on their availability at the time of the interviews. However, so as to have a have a wide representation of disciplines they were also chosen to represent at least two different subjects in each of the five colleges considered relevant for a deeper analysis. As all classifications in the College for Business Administration and
Economics had been done by one person and without adding explanations, this college was not chosen for interviews. We compared the notes from these interviews and sorted them into the main issues covered in the questionnaire used as the guideline for the interviews. The 13 persons interviewed is a small sample of all the faculty members at the University, which limits generalizability. However, these interviews offered the possibility of identifying new issues and allowed us to gain a better understanding of the actions taken and the arguments of the individuals.

Although it is likely that some of those interviewed were affected in their replies by one of the interviewers, whom they recognised as a key person in the introduction of the classification system and the environmental management system in general, most of them appeared to reply with directness. We did not perceive that the interviewees were deliberately hiding any critical comments. This openness has also been observed in other studies made at the University by different people in connection to EMS implementation (Erenlöf \& Flodin, 2007; Abasi, Hannula \& Nord, 2007) and has also been mentioned in comments in connection to the environmental audits, which are a mandatory part of the certified environmental management system.

\section{Results}

\section{Classification of Courses}

Table 1 shows how the instructors classified their courses with the codes A$\mathrm{D}$ (explained above). The table also shows the proportion of courses classified with an added explanation. It further shows that a clear majority of courses have been classified but that there are considerable differences among the departments. 
Table 1: Courses and Classifications

\begin{tabular}{|c|c|c|c|c|c|c|c|}
\hline \multirow[b]{2}{*}{ Colleges } & \multirow[b]{2}{*}{$\begin{array}{l}\text { Number of } \\
\text { courses }\end{array}$} & \multirow[b]{2}{*}{$\begin{array}{c}\% \text { not } \\
\text { classified }\end{array}$} & \multicolumn{5}{|c|}{ Classified courses } \\
\hline & & & $\% A$ & $\% \mathrm{~B}$ & $\% \mathrm{C}$ & $\% \mathrm{D}$ & $\begin{array}{l}\% \text { of classified courses } \\
\text { with explanations }\end{array}$ \\
\hline $\begin{array}{l}\text { Business Administration } \\
\text { and Economics }\end{array}$ & 149 & 0 & 6 & 29 & 51 & 14 & 0 \\
\hline $\begin{array}{l}\text { Humanities and Social } \\
\text { Sciences }\end{array}$ & 308 & 25 & 6 & 30 & 12 & 25 & 51 \\
\hline $\begin{array}{l}\text { Technology and Built } \\
\text { Environment }\end{array}$ & 252 & 25 & 10 & 36 & 13 & 17 & 73 \\
\hline $\begin{array}{l}\text { Mathematics, Natural and } \\
\text { Computer Sciences }\end{array}$ & 341 & 28 & 16 & 17 & 7 & 32 & 20 \\
\hline $\begin{array}{l}\text { Education and } \\
\text { Psychology }\end{array}$ & 150 & 39 & 7 & 35 & 7 & 12 & 79 \\
\hline $\begin{array}{l}\text { Health Sciences and } \\
\text { Sociology }\end{array}$ & 117 & 65 & 1 & 21 & 12 & 1 & 100 \\
\hline Total & 1317 & $28 *$ & 9 & 27 & 15 & 21 & 44 \\
\hline
\end{tabular}

Classification system: $A=$ a major part of the course has $E / S D$ content; $B=$ the course has some $E / S D$ content; $C=$ the course has not yet any E/SD content, but has the potential for that; $D=E / S D$ content is not relevant for this course.

* $28 \%$ not classified is valid for all courses since 2002. $18 \%$ of courses offered during the year 2005 were not classified.

Figures 2 and 3 show how the courses have been classified on the different dimensions of sustainable development. Figure 2 shows all classified courses that have an explanation, which allowed us to specify the course as reflecting the environmental dimension. These results are curious in that the expected dominance of the environmental dimension of sustainable development, as found by Ferrer-Balas et al. (2006) in their study of technical universities, is, at the University of Gävle, only true in the Department of Mathematics, Natural and Computer Sciences and the Department of
Technology and Built Environment. Many of these courses also demonstrated connections to other dimensions of sustainability in the explanations; and the results in the other departments such as Humanities and Social Sciences, Education and Psychology, and Health Sciences and Sociology where social and cultural dimensions dominate, show a different picture. Figure 2 also shows the percentage of the courses that have not only the environmental dimension, but in addition one (2d), two (3d) or three (4d) of the other sustainability dimensions.

\section{Environmental dimension of sustainable development} in courses

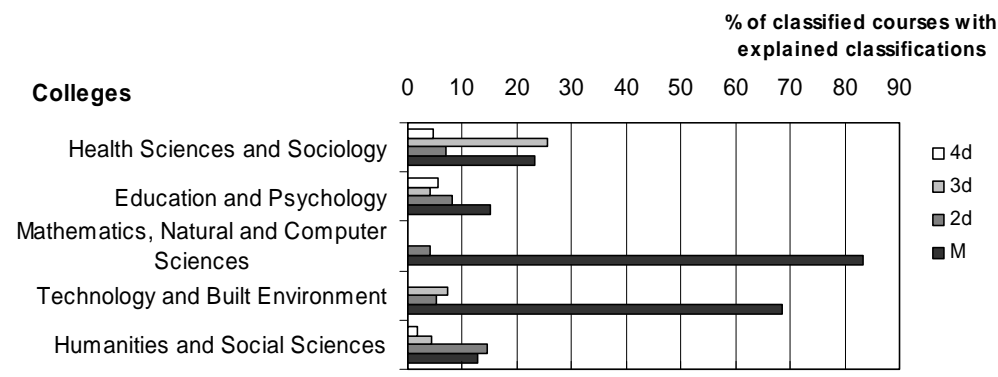

Figure 2. The percentage of courses in the five colleges classified as having an environmental dimension (M) of sustainable development. 2d, 3d, 4d include the environmental dimension together with one, two or three other dimensions of sustainability (economic, social and/or cultural). 


\section{Social dimension of sustainable development in courses}

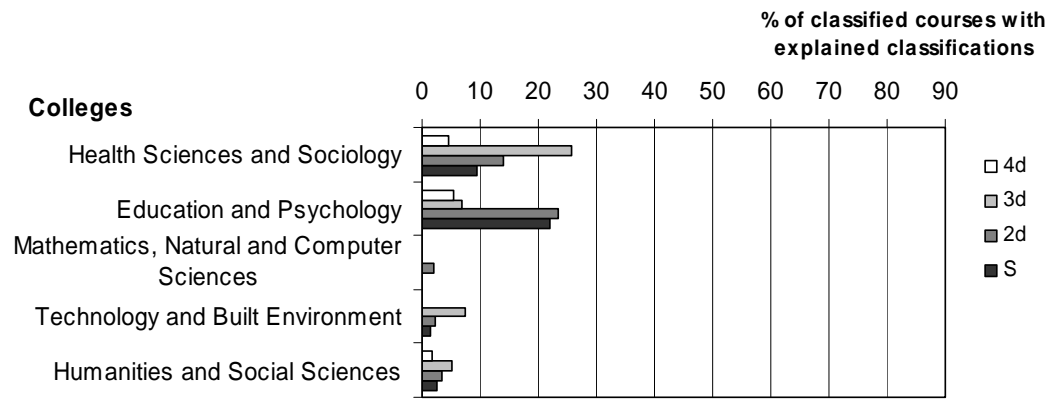

Figure 3. The percentage of courses in the five colleges classified as having a social dimension (S) of sustainable development. 2d, 3d, $4 \mathrm{~d}$ include the social dimension together with one, two or three other dimensions of sustainability (environmental, economic and cultural).

Figure 3 is similar to Figure 2 but focuses on the social (S) dimension as the first of the sustainability dimensions.

\section{Classification of Research Projects}

For 2005 there were 125 applications for research funding of which $90 \%$ were E/SD classified; and $71 \%$ of this number included explanations of the classification. Seventeen percent of the classifications with explanations were classified as A the research project represents a major contribution to $\mathrm{E} / \mathrm{SD}$ ); and nearly half, $49 \%$, were classified as B (the research project represents a minor contribution to E/SD). Sixteen percent of project managers indicated that a contribution to a E/SD was not relevant to their project, and $7 \%$ were not sure of the project's contribution to E/SD. It appears that most of the research applications with explanation of the classification included more than one dimension of sustainability. Thirty-two percent of the applications combined the social dimension with one other dimension, while the corresponding figures for a twodimensional combination with environmental and cultural aspects are also frequent: $21 \%$ and $20 \%$ of the research projects.

\section{Interviews}

In the interviews the instructors/ researchers were asked about their experiences with the classification system, the outcomes, and their definitions of sustainable development. Nine of the thirteen interviewees had discussed the classification of their course(s) with their colleagues, three had done it alone, and one did not remember how he had done it since he is "allergic" to all kinds of forms. No one was concerned about the time required for this process. The difficulty for half of the interviewees was that they were forced to think about "new things ... never thought about before". (N.B. All comments from the interviews have been translated from Swedish to English by the authors of this article.) One instructor commented: "Our first reflection was that it is something big, and not relevant to us. Then we started thinking that maybe there is something in it, and finally we saw it with a longer perspective, that this is right for us." Several of them mentioned having a lot of discussion about the issue in various groups. Two instructors had experienced difficulties later when the initial environmental dimension was extended to other perspectives of sustainability. 
The three interviewees who were most critical of the procedure saw the classification as a forced administrative exercise from the top, and one commented that it was "the least amount of trouble to fill out the form and send it further" rather than to start a discussion about the procedure. The lack of importance of the issue, they claimed, was illustrated by the fact that there is nothing about such issues in the self-evaluations required by the Swedish National Agency for Higher Education. However, one of them stated that he has now started thinking more about the direct environmental aspects, such as material use, in his course.

Ten interviewees defined sustainable development mainly in environmental terms such as use of scarce resources and recycling. Two of them talked of it as being linked to economic and worker health and safety issues: "For example the design of a factory also affects the need for transport and consequently energy consumption." One more critical voice saw sustainable development as an "uninteresting political buzz word" along the lines of the classless society in the 1980s, and thus a policy area for the government. Two of the interviewees pointed to a broader perspective: "Culturally, every generation must win back, for example, democracy. The more open and democratic a society is, the better the environment." Or even wider: "With every step you take you should be aware of and responsible for the consequences of your actions."

Although it is not possible to attribute all changes in courses to the classification process, it is apparent that changes have taken place according to eight of the interviewees. One has changed the course plan by adding a new lecture or assignment concerning environmental issues related to the subject in question. Several of the interviewees said they were more aware of the importance of proactive environmental thinking and also aware of the potential for environmental impact through indirect measures, such as teaching. Not all of them had made conscious changes in their courses, but among those who had not made any changes one commented that he was now more ready to answer student questions about these issues. One instructor regularly shows the classification form to her students at the beginning of the course so as to raise their attention to these issues. The direct environmental impact of using fewer printouts and copies were mentioned by one lecturer, whereas another one, who had initially been motivated by such direct aspects of paper usage, was now thinking in terms of the course content.

When asked about how they believed the forms were used after they had been filled out, ten of the interviewees assumed that they were filed and used for internal and external statistical reporting or the environmental audits mandated by the certified environmental management system. Only a few of them had previously thought about usage of the forms. Six of them remembered receiving feedback from the head of department or the environmental coordinator after the classification form was submitted. One person indicated there is a problem with the overwhelming amount of information: "You only take in what appeals to you and leave out what you do not need; there is a high barrier to what you are listening to." An instructor who had experience with quality management practices in industry drew a parallel: "If you do not have follow-up, you cannot see the continuous improvements and the system is just paper in files."

\section{Suggestions for Improvement}

Six interviewees brought up the benefit of discussing the classification with colleagues, preferably including someone with knowledge and competence 
concerning environmental issues. It was also perceived as beneficial if the college head participates or even leads such discussions so that efforts are coordinated throughout the curriculum, which provides better opportunities for feedback to the instructors.

Other suggestions for improvement included a detailed manual with checklists for the course classification, preferably with examples from every department. Although a simple approach was appreciated, one interviewee suggested that there could be more questions on the classification forms to stimulate deeper reflection, "since our values are formed during our education, and reflection reduces mistakes". One instructor asked for more feedback and opportunities to increase one's holistic awareness. This request could easily be met by discussion in departmental meetings or through information provided to faculty in print. Those who opposed this formal classification system suggested that classification should be done "only when it is relevant, for example, in teacher training programs". Another proposal was that the integration should be limited to discussions with students and colleagues when need arises. In contrast, three instructors pointed to the need to change the culture of the whole organization and to allocate resources to implement real change.

\section{Discussion}

The results of the study of the classification forms reveal some interesting differences. It is tempting to explain the predominance of the environmental perspective in the College of Mathematics, Natural and Computer Sciences and the College of Technology and Built Environment with traditionally closer linkages to environmental issues. It does not seem to be very difficult for the faculty members in these departments to relate to environmental issues, which may stop them from even starting to explore other dimensions of sustainable development, or, at least, to remember it when, for instance, asked about the sustainability content of their courses. Initially, it may also be difficult for them to comprehend the other dimensions. In colleges such as Humanities and Social Sciences; Education and Psychology; and Health Sciences and Sociology, the opposite could be the case. Since the faculty members in these departments are not accustomed to relate their disciplines to environmental issues, they have found other connections to the definitions of sustainable development. This finding is encouraging since it seems to indicate that instructors have reflected on the issue and have identified what could be relevant for their courses. We would definitely consider this as a first necessary step to engage new instructors in the sustainability work.

According to Holt (2003), who has studied the impact of environmental modules for students in business schools, discipline-specific modules appear to benefit students most. Therefore, it is interesting to see that several of the dimensions of sustainability can be integrated into disciplinary-oriented courses within an academic department. Even when the courses with sustainable development content constitute only a minor part in a departmental curriculum, they can act as showcases of how to integrate sustainable development in one or several dimensions.

We agree with Sterling (2004), who claimed that integrating sustainability into "normal" courses and research projects at a university is the best way of reaching the students and equipping them with effective tools and knowledge to work for sustainability in their future careers. In this context, it is encouraging to see that all departments have identified links to their own courses even though it can still be debated how far the various 
departments have actually come in furthering integration of the sustainability perspective. It is a fact that the present classification system does not necessarily demand much change, or maybe even none, to allow for a "higher" classification of a course as the classification is based on interpretation by the individual instructors. However, the interviews strongly indicated that several of the instructors have taken the first steps, mentally and/or practically, towards real change.

We did not explore whether the high degree of classification of research projects is due to familiarity with the course classification or if it can be attributed to a perceived increase of the chances of receiving funding from the University, despite the fact that it has been clearly stated that it is not part of the criteria for financing.

As shown by the interviews, the environmental dimension is the most likely starting point for most instructors; but the interviews also indicated that, once the process has started, it can easily develop so as to include additional dimensions of sustainability. The authors believe this development could be enhanced if the procedure would be developed further so that, instead of classifying the courses and projects only according to the level of integration (A $\mathrm{D})$, instructors and researchers would directly classify and explain what dimensions of sustainable development are relevant for the course or the project. This would also eliminate the present need for interpreting the explanations for the particular classification selected by instructors and researchers. However, also in a more elaborate system, there is likely to be a certain overlap between the various dimensions of sustainability.

One problem with the approach studied arises when having the classification done by someone knowledgeable in environmental matters is considered more important than having faculty members classifying their own courses. Indeed, the environmental coordinator in each department, with knowledge of the subject area, may be quite capable of making the classification. However, then the instructor's reflection through the process of thinking through the classification procedure is lost; and consequently the most important trigger for change is at risk of being lost.

It is also evident from comments of interviewees and informal comments from other faculty members that this study, particularly due to the impetus of the interviews, provided a push for the instructors and researchers to reflect on the work of integrating sustainability into teaching and research. The interviews and the study itself became a form of feedback and a sign of interest in their efforts.

It would be interesting to see more studies of similar types of initiatives in other universities so as to evaluate better the potential for promoting the introduction of sustainability into teaching and research efforts and to have a broader basis for suggesting refinement of approaches and initiatives. In our case, the introduction of the classification process was simplified as it was designed to be part of the environmental management system.

\section{Conclusion}

Our aim was to study an institutional procedure designed to stimulate integration of the concept of sustainable development into courses and research projects. We gained a number of valuable insights and we recommend this procedure or similar ones to other institutions.

The method of classifying courses provides a framework to approach the issue of sustainable development from common definitions, but still allows for individual interpretations and approaches 
to integrating the issues in courses and research. The experience at the University of Gävle clearly shows that it is possible to integrate the concept of sustainable development into higher education in meaningful ways and to address the main dimensions of sustainability - environmental, social, economic and cultural, and their different combinations.

An important finding of the study is that the feedback system needs further development in order to show instructors and researchers that the integration of sustainability is seen as important to the university administration and to promote deep and continuous reflection about course content and research design. The national authorities could support integration of the sustainability concept further by imposing similar requirements in the regular evaluations of all universities by the Swedish National Agency for Higher Education and the research applications for state funding.

\section{Acknowledgements}

The authors want to thank the faculty at the University of Gävle, who in various ways have contributed to this study.

\section{References}

Abasi, D., Hannula, H., \& Nord, J. (2007). Miljöarbetet och dess förändringar vid Högskolan $i$ Gävle (An environmental management system implementation as a change process. A case study at the University of Gävle). Unpublished M.Sc. thesis, University of Gävle, Sweden.

Appel, G., Dankelman, I., \& Kuipers, K. (2004). Disciplinary explorations of sustainable development in higher education. In B.P. Corcoran \& A. E. J. Wals (Eds.). Higher education and the challenge of sustainability. Problems, promise, and practice (pp. 213-222). Dordrecht, The Netherlands: Kluwer Academic Publishers.

Corcoran, B. P., \& Wals, A. E. J. (Eds.) (2004). Higher education and the challenge of sustainability. Problems, promise, and practice. Dordrecht, The Netherlands: Kluwer Academic Publishers.
Erenlöf, C., \& Flodin, P. (2004). Förändringsarbete $i$ organisation (Changing an organisation). Unpublished B.Sc. thesis, University of Gävle, Sweden.

Ferrer-Balas, D., Cruz, Y., Segalàs, J., \& Sans, R. (2005). Lessons learned from our particular "decade" on education for sustainability (1996-2005) at UPC. In J. Holmberg \& B. E. Samuelsson, Drivers and barriers for learning for sustainable development in bigher education. Education for Sustainable Development in Action. Technical Paper; 32006. UNESCO Education Sector.

Fisher, R. M. (2003). Applying ISO 14001 as a business tool for campus sustainability: A case study from New Zealand, International Journal of Sustainability in Higher Education, 4, 138-150.

Flint, K. (2001). Institutional ecological footprint analysis. A case study of the University of Newcastle, Australia. International Journal of Sustainability in Higher Education, 2, 4862.

Herremans, I., \& Allwright, D.E. (2000). Environmental management systems in North American universities. What drives good performance? International Journal of Sustainability in Higher Education, 1, 168-181.

Holt, D. (2003). The role and impact of the business school curriculum in shaping environmental education at Middlesex University. International Journal of Sustainability in Higher Education, 4, 324-343.

Juárez-Nájera, M., Dieleman H., \& TurpinMarion S. (2006). Sustainability in Mexican higher education: Towards a new academic and professional culture. Journal of Cleaner Production, 14, 1028-1038.

Lidgren, A., Rodhe, H., \& Huisingh, D. (2006). A systemic approach to incorporate sustainability into university courses and curricula. Journal of Cleaner Production, 14, 797809.

Orr, D. W. (1996). Reinventing Higher Education. In J. Collett \& S. Karakashian (Eds.) Greening the college curriculum. Guide to environmental teacbing in the liberal arts (pp. 8-23). Washington, DC: Island Press.

Penn State Green Destiny Council (2000). Penn State indicators report - 2000 - Steps towards a sustainable university. Retrieved January 31, 2007, from http://www.bio.psu.edu/

Greendestiny/publications.shtml

Price, T. J. (2005). Preaching what we practice: experiences from implementing ISO 
14001 at the University of Glamorgan. International Journal of Sustainability in Higher Education. 6, 61-178.

Ruy, H-C., \& Brody, S. D. (2006). Examining the impacts of a graduate course on sustainable development using ecological footprint analysis. International Journal of Sustainability in Higher Education. 7, 158-175.

Sammalisto, K. (1999). Greening experiences and ambitions as seen by students at some Swedish universities. Retrieved August 24, 2006, from http://www.hgur.se/envir/library.html

Sammalisto, K. (2004, June). From government directive to sustainable development in Swedish universities. Does an EMS give results? Proceedings of the EMSU conference, Monterrey, Mexico.

Sammalisto, K., \& Arvidsson, K. (2005). Environmental management in Swedish higher education. Directives, driving forces, hindrances, environmental aspects and environmental co-ordinators in Swedish universities. International Journal of Sustainability in Higher Education, 6, 18-35.

Sammalisto, K., \& Brorson, T. (2006). Training and communication in the implementation of environmental management systems (ISO 14001). A case study at the University of Gävle, Sweden. Journal of Cleaner Production. Available online 28 September 2006. doi:10.1016/j.jclepro.2006.07.029.

Segalàs, J., Cruz, Y., \& Mulder, K. (2004, October). What professionals should know about sustainable development? ENCOS. European network conference on sustainability practice, Berlin, Germany.

Segalàs, J., Ferrer, D., \& Carrillo, A. (2004, October). Sustainability Evaluation of Engineering Student Projects: A Guideline for the Sustainability Award by CETIB-UPC. International Conference on Engineering Education in
Sustainable Development, EESD2004. Barcelona, Spain.

Segalàs, J., Ferrer-Balas, D., \& Mulder, K. (2005, October). Curriculum greening in engineering education. Experiences from Dutch and Spanish technological universities. 3rd World environmental education congress, Torino, Italy.

SFS 1992:1434. Högskolelagen (1992:1434) (The Higher Education Act. Amendment valid from February 1, 2006).

Shriberg, M. (2002). Institutional assessment tools for sustainability in higher education. Strengths, weaknesses, implications for practice and theory. International Journal of Sustainability in Higher Education,3, 254-270.

Stanley, C. A. (2000-01). Teaching in action: Multicultural education as the highest form of understanding. Essays on Teaching Excellence, 12 (3) Nederland, CO: The Professional and Organizational Network in Higher Education.

Sterling, S. (2004). Higher education, sustainability, and the role of systematic learning. In B.P. Corcoran \& A. E. J. Wals (Eds.). Higher education and the challenge of sustainability. Problems, promise, and practice (pp. 49-70). Dordrecht, The Netherlands: Kluwer Academic Publishers.

Swedish Code of Statues (1992). Högskolelagen (1992:1434) (The Higher Education Act. Amendment valid from February 1, 2006).

UNESCO. (2002). Decade of Education for Sustainable Development, Accessed 2006-04-25, http://portal.unesco.org/education/en/ev.ph

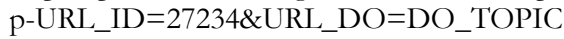
\&URL_SECTION=201.html

Wright, T. S. A. (2004). The evolution of sustainability declarations in higher education. In B.P. Corcoran \& A. E. J. Wals (Eds.). Higher education and the challenge of sustainability. Problems, promise, and practice (pp. 7-19). Dordrecht, The Netherlands: Kluwer Academic Publishers. 